\title{
Photoelastic evaluation of the effect of composite formulation on polymerization shrinkage stress
}

Karla Mychellyne Costa Oliveira ${ }^{(a)}$ Simonides Consani ${ }^{(a)}$

Luciano Souza Gonçalves $^{(\mathrm{b})}$

William Cunha Brandt ${ }^{(c)}$

Renzo Alberto Ccahuana-

Vásquez $^{(\mathrm{d})}$

\footnotetext{
(a) Department of Dental Materials, Piracicaba Dental School, State University of Campinas, Piracicaba, SP, Brazil.

(b) Department of Restorative Dentistry, University of Uberaba, Uberaba, MG, Brazil.

${ }^{(c)}$ Department of Prosthodontics, Dentistry School, University of Taubaté, Taubaté, SP, Brazil.

(d) Department of Comprehensive Dentistry, University of Texas Health Science Center, San Antonio, TX, USA.
}

Abstract: We compared polymerization stress in two commercial composites and three experimental composites made using camphorquinone (CQ) and/or phenylpropanedione (PPD) as photoinitiators. The internal surfaces of photoelastic resin discs with cylindrical cavities were roughened and treated with adhesive. Composites were divided into five groups: two commercial composites (Filtek Silorane and Filtek Z250) and three experimental composites with CQ/amine, CQ/PPD/amine, and PPD/amine. Composites were photopolymerized inside cavities, and subjected to photoelastic analysis immediately and at 24 hours and 7 days later using a plane polariscope. Stress created by Silorane $(3.08 \pm 0.09 \mathrm{MPa})$ was similar to that of Z250 (3.19 $\pm 0.13 \mathrm{MPa}) \mathrm{im}-$ mediately after photopolymerization $(\mathrm{p}>0.05)$. After 24 hours and 7 days, Z250 (3.53 \pm 0.15 and $3.69 \pm 0.10 \mathrm{MPa}$, respectively) showed higher stress than Silorane (3.19 \pm 0.10 and $3.16 \pm 0.10 \mathrm{MPa}$, respectively). Qualitative analysis immediately after photopolymerization showed composite/CQ promoted higher stress than PPD, but stress levels at other evaluated times were statistically similar, varying between $3.45 \pm 0.11 \mathrm{MPa}$ and $3.92 \pm 0.13 \mathrm{MPa}$. At 24 hours and 7 days, Silorane created the lowest stress. All photoinitiators created comparable tensions during polymerization.

Descriptors: Composite Resins; Polymerization; Photoinitiators, Dental; Dental Stress Analysis.

\section{Introduction}

Dental composites are polymer-based materials that shrink during polymerization. Stress occurs when shrinkage is limited and the material is rigid and flow resistant. ${ }^{1}$ These stresses may cause imperfections at the bond interface, allowing marginal leakage and bacterial contamination. ${ }^{2}$ Many factors-including some that are related to material composition such as organic matrix composition, initiation system, and amount of inorganic filler-affect the degree of polymerization shrinkage, influencing contraction and strain. ${ }^{3-5}$

The organic matrices of composites contain different monomers. Recently, a new silorane-based monomer composite was introduced for use in dentistry. The silorane polymer chain is formed by cationic ring opening and involves the action of three initiator components. Ring opening results in molecular expansion that compensates for polymerization shrinkage. ${ }^{6}$ Thus, stresses generated by polymerization processes associated with silorane are lower than those associated with methacrylate-based composites?

Most composites include camphorquinone (CQ) as a photoinitiator agent
Received for publication on Oct 13, 2011 Accepted for publication on Jan 18, 2012
Karla Mychellyne Costa Oliveira

E-mail: karlamychellyne@yahoo.com 
and an amine acting as co-initiator. ${ }^{8}$ 1-Phenyl-1,2-propanedione (PPD) has been suggested as a possible CQ substitute, with the potential to reduce discoloration and improve the aesthetic properties of composites. ${ }^{9}$ Generally, PPD-containing composites attain maximum polymerization values more slowly than those with $C Q$, because the polymerization rate and degree of conversion depend on the absorbed power density. ${ }^{10}$

The aim of this study was to use photoelastic analysis to evaluate polymerization shrinkage stress. Photoelastic analysis is a visual measurement based on the property of some transparent materials to exhibit interference fringes when stressed in a polarized light field. This technique has been used previously to evaluate polymerization shrinkage stress in dental composites., ${ }^{4,11}$ These fringes have mathematical relationships and order numbers that are dependent on the load intensity applied to the photoelastic material. ${ }^{12,13}$ In this study, stress induced in three experimental and two commercial composites was assessed immediately after photopolymerization and 24 hours and 7 days later.

\section{Methodology}

\section{Composites composition}

Commercial composites were Filtek Silorane (Silorane) and Filtek Z250 (Z250) (3M ESPE, St. Paul, USA) prepared using Adper Single Bond 2 and Silorane adhesive systems (3M ESPE).

For experimental composites, the organic matrix was composed of the dimethacrylate monomers bisphenol A glycidyl dimethacrylate (Bis-GMA, Aldrich Chemistry, São Paulo, Brazil), ethoxylated bisphenol A dimethacrylate (Bis-EMA, Aldrich), urethane dimethacrylate (UDMA, Aldrich), and triethyleneglycol dimethacrylate (TEGDMA, Aldrich). The inorganic matrix was composed of Bario Aluminium Silicate (BaAlSi, $0.5 \mu \mathrm{m}$,
Biodinâmica, Ibiporã, Brazil) and 20 wt.\% silicon dioxide $\left(\mathrm{SiO}_{2}, 0.04 \mu \mathrm{m}\right.$, Biodinâmica). Both were treated with 3\% methacryloxipropyl trimethoxisilan. The initiator agents were CQ (Aldrich) and PPD (Aldrich), the reducing agent was dimethyl amino ethyl methacrylate (DMAEMA) (Aldrich), and the inhibitor was butylated hydroxytoluene (0.1 wt.\%) (Aldrich). The composition of the experimental composites is presented in Table 1. Experimental composites were prepared at room temperature under low illumination by first preparing separate organic and inorganic matrices and then mixing these phases.

\section{Specimen preparation}

Araldite GY 279 photoelastic base resin and Aradur 2963 catalyst (Araltec Produtos Químicos, São Paulo, Brazil) were used to fabricate discs $20 \mathrm{~mm}$ in diameter, $2 \mathrm{~mm}$ thick, with a central perforation $6 \mathrm{~mm}$ in diameter. Inner preparation surfaces of Araldite resin discs were roughened using a bench drill to improve photoelastic resin-composite bonding. Discs were stored at $37^{\circ} \mathrm{C}$ for 24 hours to allow relief of photoelastic resin stress. Before specimen preparation, each disc was placed in the photoelastic device to assess residual stress. If any was detected, the disc was stored in an oven at $37^{\circ} \mathrm{C}$ for 24 hours until stress was completely released.

Photoelastic discs were separated into five groups $(\mathrm{n}=5$ each):

- Silorane,

- Z250,

- Experimental I (CQ),

- Experimental II (CQ/PPD), and

- Experimental III (PPD).

The inner surfaces of Araldite discs were treated with the appropriate adhesive system for each composite

\begin{tabular}{|c|c|c|c|c|}
\hline \multirow{3}{*}{$\begin{array}{r}\text { Table } 1 \text { - Composition } \\
\text { of experimental } \\
\text { composites } \\
(\text { in wt. } \%)\end{array}$} & \multirow{2}{*}{ Composites } & \multicolumn{2}{|c|}{ Organic matrix (40 wt.\%) } & \multirow{2}{*}{ Filler (60 wt.\%) } \\
\hline & & Monomers & Initiation system & \\
\hline & Experimental I & \multirow{3}{*}{$\begin{array}{c}\text { Bis-GMA } \\
(29 \%) \\
\text { UDMA }(31 \%) \\
\text { Bis-EMA }(31 \%) \\
\text { TEGDMA }(7 \%)\end{array}$} & CQ/amine $(0.4 / 0.8 \%)$ & \multirow{3}{*}{$\begin{array}{l}\mathrm{BaAlSi}, 0.5 \mu \mathrm{m}(80 \%) \\
\mathrm{SiO}_{2}, 0.04 \mu \mathrm{m}(20 \%)\end{array}$} \\
\hline & Experimental II & & $\mathrm{CQ} / \mathrm{PPD} /$ amine $(0.2 / 0.2 / 0.8 \%)$ & \\
\hline & $\begin{array}{l}\text { Experimental } \\
\text { III }\end{array}$ & & $\mathrm{PPD} / \mathrm{amine}(0.4 / 0.8 \%)$ & \\
\hline
\end{tabular}

Bis-GMA, bisphenol A glycidyl dimethacrylate; BIS-EMA, ethoxylated bisphenol A dimethacrylate; UDMA urethane dimethacrylate; TEGDMA, triethyleneglycol dimethacrylate; $\mathrm{CQ}$, camphorquinone; PPD, 1-phenyl-1,2- 
following the manufacturer's instructions. A bulk increment of composite was placed in the central perforation of the photoelastic disc and polymerized using an LEDbased dental curing unit (Ultra-Lume LED 5, Ultradent Products Inc., South Jordan, USA) set at $890 \mathrm{~mW} / \mathrm{cm}^{2}$ in standard exposure mode for 60 seconds to induce maximum stress in the composite.

\section{Optical calibration}

To obtain the photoelastic constant $\left(f_{\sigma}\right)$ of Araldite resin, optical calibration was performed. ${ }^{14}$ Briefly, a beam of photoelastic resin was loaded using the fourpoints bending method, which produces stress patterns of pure bending, generating horizontal isochromatic fringes from a neutral axis on the center of the beam. According to a plot of $3 \mathrm{~Pa}$ versus $h^{2} N$, the mean coefficient value was $f_{\sigma}=11271 \mathrm{~N} / \mathrm{m}$.

\section{Photoelastic analysis}

Photoelastic images were recorded with a 2.1-megapixel digital camera (FD Mavica, Sony model MVCFD97, Tokyo, Japan) at three time points (immediately after light activation and 24 hours and 7 days post-polymerization) in a plane photoelastic device with exact filter angulations (90 degrees) to obtain constant colored fringes. Next, a red filter was placed between the light source and the first polarized lens to obtain constant light and dark fields on images. Fringes formed on the photoelastic resin were qualitatively analyzed based on the Stress-Optical Law. ${ }^{15}$

\section{Photoelastic measurements}

Polymerization shrinkage stress data (in $\mathrm{MPa}$ ) were calculated based on the methodology of Ernst et al. ${ }^{4} \mathrm{Ba}-$ sically, three measurements of the first-order photoelastic fringe obtained from Araldite discs were obtained from each specimen $(n=5)$ on monochromatic images using UTHSCSA ImageTool software (University of Texas, San Antonio, TX, USA; available without cost from ftp://maxrad6.uthscsa.edu). Shrinkage stress values $\left(\sigma_{0}\right)$ were obtained from the isochromatic ring diameters using the following equation:

$$
\sigma_{0}=\left(N_{\mathrm{x}} D_{\mathrm{x}}^{2} f_{\sigma}\right) /\left(D_{\mathrm{i}}^{2} 2 d\right)
$$

where $N_{\mathrm{x}}$ is the isochromatic ring order, $D_{\mathrm{x}}$ is the iso- chromatic ring diameter $(\mathrm{mm}), D_{\mathrm{i}}$ is the disc preparation diameter $(\mathrm{mm}), f_{\sigma}$ is the photoelastic constant $(\mathrm{N} / \mathrm{mm})$, and $d$ is the disc thickness $(\mathrm{mm})$.

Homogeneity and homoscedasticity tests were performed to confirm normality of the data. The mean of the shrinkage stress values was obtained, and the data were statistically analyzed considering the five groups and the three different times for each group. The same data sets were analyzed for the different times using Repeated Measures ANOVA followed by the Bonferroni test. $\mathrm{P}$ values $<0.05$ were considered significant.

\section{Results}

Each rainbow band corresponded to the first-order isochromatic fringe and, when monochromatic light was used, each line represented a fringe. The fringe appeared when a fixed amount of deformation occurred on the photoelastic disc. Thus, the fringes are directly related to the deformations created in the photoelastic resin by the polymerization shrinkage process.

\section{Qualitative analysis}

Images taken under white light showed colored fringe formation around the composite. Greater color variation indicates more stress in the photoelastic material. Photoelastic resin from the group with Silorane showed the lowest stress, as characterized by a yellow fringe formation that darkened over time (Figure 1). This yellow fringe was also observed with Z250 immediately after photoactivation. After 24 hours, fringes were thicker and had greater color variation. After 7 days, the color variation was even more evident. For the experimental composites, the CQ group promoted the highest stress in photoelastic resin (Figure 2). CQ images taken immediately after photoactivation showed fringe stresses with clear colors, indicating a high stress level in the photoelastic disc. Images taken after 24 hours showed an increase in stress, with formation of a new green fringe. This new fringe formed indicated an increasing stress pattern after 7 days. Images generated for the CQ/PPD group immediately after photoactivation showed a pattern indicating lower stress than in the CQ group. After 24 hours, fringes with greater color variation were observed, and stress was slightly increased after 7 days. For the PPD group, the photoelastic 

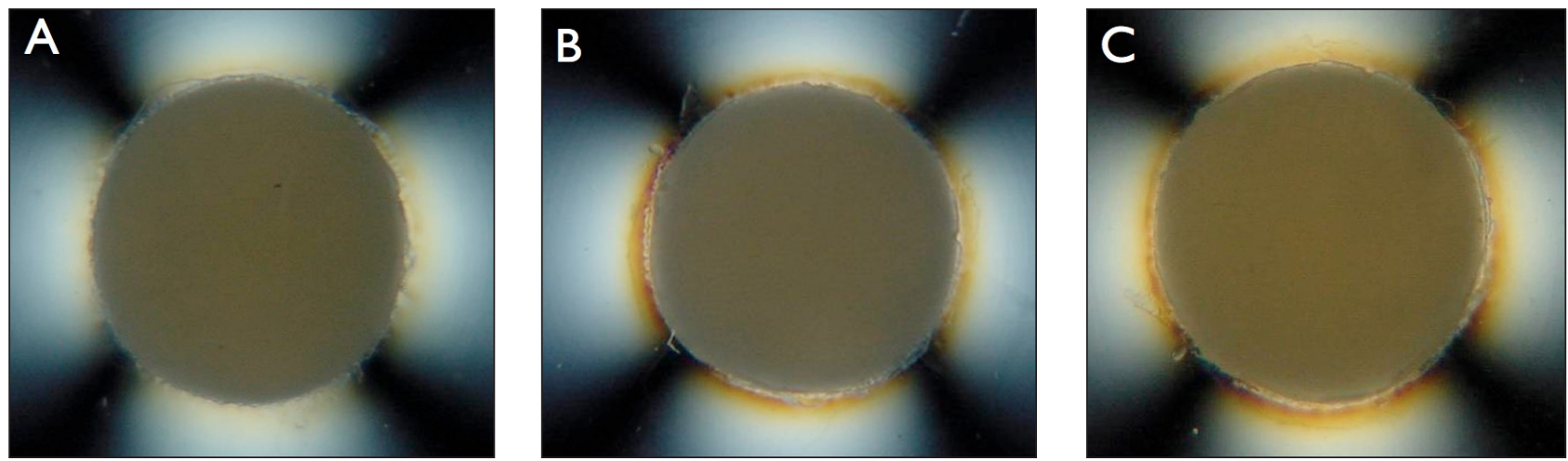

Figure 1 - Stress fringes generated by commercial Silorane photoelastic resin immediately after photopolymerization (A) and 24 hours (B) or 7 days (C) later.
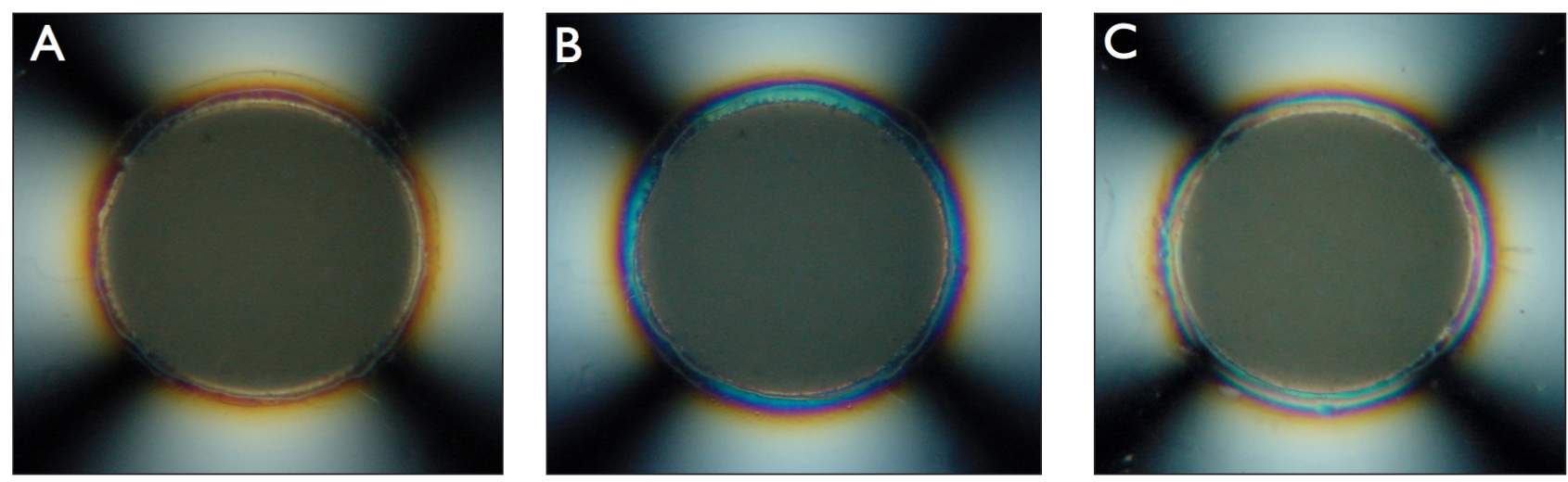

Figure 2 - Fringes formed by experimental CQ resin immediately after photopolymerization (A) and 24 hours (B) or 7 days (C) later.

resin showed an orange fringe with some darker areas immediately after photoactivation, characterizing lower stress than in the CQ and CQ/PPD groups. Completely blue fringes were seen at 24 hours, and the beginning of a new fringe formation was observed at 7 days.

\section{Quantitative analysis}

Table 2 shows the calculated stress values. No statistical difference between commercial composites was observed upon immediate evaluation $(\mathrm{p}>0.05)$. After 24 hours and 7 days, the Z250 composite showed higher stress than Silorane $(\mathrm{p}<0.05)$. The experimental composites were statistically equivalent at all evaluation times $(p>0.05)$. Stresses evaluated immediately after photoactivation were statistically lower than those after 24 hours and 7 days $(p<0.05)$, except for the silorane composite. Stresses observed after 24 hours and 7 days did not differ statistically for any composite tested $(p>0.05)$.

\section{Discussion}

Photoelastic images revealed composite polymerization shrinkage stress. According to the literature, the resulting volumetric contraction is directed towards the center of the material mass, and the distribution of stress is controlled by free surfaces and bond quality. ${ }^{11}$ In this study, the isochromatic fringe pattern was the result of traction forces that the composite induced on the photoelastic resin, suggesting that the resulting contraction occurred towards the material center, as previously suggested. ${ }^{11}$

Commercial composites showed lower polymerization shrinkage stress than experimental composites. The percentage of organic matrix was higher in the experimental composites (40 wt.\%) than in the Z250 matrix (18 wt.\%, according to the manufacturer). Composites 
Table 2 - Polymerization shrinkage stress values $(\mathrm{MPa})$ and standard deviation of commercial and experimental composites at three evaluation times $(n=5)$.

\begin{tabular}{l|c|c|c}
\hline \multirow{2}{*}{ Group (Composites) } & \multicolumn{3}{|c}{ Time } \\
\cline { 2 - 4 } & Immediate & 24 hours & 7 days \\
\hline 1. Silorane & $3.08(0.09) \mathrm{aA}$ & $3.19(0.10) \mathrm{aA}$ & $3.16(0.10) \mathrm{aA}$ \\
\hline 2. Z250 & $3.19(0.13) \mathrm{aA}$ & $3.53(0.15) \mathrm{bB}$ & $3.69(0.10) \mathrm{bB}$ \\
\hline 3. Experimental I & $3.64(0.19) \mathrm{bA}$ & $3.84(0.16) \mathrm{cB}$ & $3.87(0.17) \mathrm{cB}$ \\
\hline 4. Experimental II & $3.59(0.17) \mathrm{bA}$ & $3.82(0.17) \mathrm{cB}$ & $3.80(0.11) \mathrm{cB}$ \\
\hline 5. Experimental III & $3.45(0.11) \mathrm{bA}$ & $3.83(0.19) \mathrm{cB}$ & $3.92(0.13) \mathrm{cB}$ \\
\hline
\end{tabular}

Values followed by the same lowercase letters in the same column and by the same capital letter in the same row are not significantly different $(\mathrm{p}>0.05)$ as determined by the Bonferroni test.

with high filler content undergo low volumetric contraction because they have less resin matrix content. ${ }^{3}$ Composites with low filler content and low contraction may undergo a rapid increase in material stiffness, resulting in high stress values. ${ }^{16}$

The results of this study confirmed that the composite resin matrix influences polymerization shrinkage stress. The Silorane composite showed the lowest stress at the three times evaluated. Statistical analysis demonstrated that Silorane and Z250 showed similar results immediately after photopolymerization, but Z250 promoted higher stress than Silorane after 24 hours and 7 days. These two composites mainly differ in the monomer used in the organic matrix. Silorane is composed of silorane monomers, whereas Z250 is composed of dimethacrylate monomers such as Bis-GMA, BisEMA, and UDMA. Dimethacrylate monomers are polymerized by $\mathrm{C}=\mathrm{C}$ double bond reactions, resulting in decreased space between the chains and consequently an increase in volumetric contraction. ${ }^{5}$ In contrast, the cationic ring-opening reactions in silorane materials are responsible for the decreased polymerization stress, generating low stress shrinkage. ${ }^{6}$

Although there were no statistically significant differences between experimental composites, qualitative analysis of images suggested that CQ composites generated more stress in photoelastic resin than $\mathrm{CQ} / \mathrm{PPD}$ or PPD composites immediately after photopolymerization. This discrepancy between qualitative and quantitative results is probably due to the difficulty in measuring some images to obtain accurate quantitative results. Some monochromatic images did not present clear fringe edges, which may have compromised the operator's ability to measure isochromatic fringe diameters.

The CQ absorption spectrum ranges from $\sim 400$ to
$500 \mathrm{~nm}$ with an absorption peak at $468 \mathrm{~nm}$, whereas PPD has a relatively wide absorption spectrum with an absorption peak at approximately $392 \mathrm{~nm} .{ }^{10}$ The spectrum emitted by LED units produces more energy within the CQ absorption spectrum. ${ }^{17}$ Thus, CQ activation was probably more efficient, so that the CQ polymerization reaction was initiated more quickly than the PPD reaction, creating fringes with greater color variation or higher polymerization stress immediately after photopolymerization. Fringes formed at 24 hours and 7 days were similar for the different initiation systems. Photopolymerization was performed using a third-generation LED unit with secondary accessory LEDs that emit a second peak of energy at $402 \mathrm{~nm}$. This probably contributed to enhanced PPD activation.

Moreover, PPD and CQ reactions are probably initiated using different mechanisms. CQ operates predominantly by proton abstraction of the amine hydrogen, whereas PPD can undergo photocleavage and proton abstraction, which forms free radicals more efficiently. ${ }^{9}$ Apparently, this had no effect on polymerization stress in this study, because PPD composites and CQ composites generated similar stress values. Thus, it appears that both photoinitiators were able to promote double link conversion; although PPD reduced the reaction velocity, this did not decrease total composite polymerization shrinkage.

Polymerization stress can be reduced without decreasing the degree of conversion when the flow capacity of the composite is increased. ${ }^{18}$ In the present study, this appears to be less apparent in composites with CQ alone. Aside from the slower polymerization rate, other factors such as lower elastic modulus and glass transition temperatures may reduce shrinkage stress. ${ }^{19}$

The composite with CQ/PPD showed intermediate 
stress fringes compared with composites with CQ or PPD alone, but the stress values were statistically similar. This probably occurred because the combination of $\mathrm{CQ} / \mathrm{PPD}$ led to an intermediate polymerization rate at the beginning of the reaction, but to a rate similar to that of CQ and PPD alone at the end of the polymerization process. This result is inconsistent with a previous study reporting a synergistic effect between CQ and PPD, suggesting that one could expect more efficient use of photon energy. ${ }^{9}$

Not all polymerization shrinkage occurs immediately after light activation. ${ }^{20}$ Our results showed that stress increased at 24 hours and remained constant at 7 days for all composites except Silorane. The contraction observed after the light source was removed may be attributed to progressive cross-linking reactions that occur after photoactivation was concluded (post-cure), and to thermal contraction due to loss of radiant heat. ${ }^{7}$ Considering that the light exposure time was similar for all groups, thermal contraction may have occurred for all composites.

Photoelastic analysis was appropriate for evaluating polymerization shrinkage stress. However, the limitations of this study include the fact that other relevant aspects of stress development could not be monitored (such as kinetic reactions and polymerization rates), and that the degree of conversion and hardness of experimental composites was not evaluated. Future studies that address these limitations will improve our understanding of polymerization shrinkage using different composites.

\section{Conclusion}

Within the limitations of this study, we conclude that polymerization shrinkage stress could be minimized by using silorane-based composites, which may cause less gap formation. Experimental composites containing

of conversion, hardness and yellowing of dental resin composites. Dent Mater. 2008 Sep;24(9):1169-77.

11. Kinomoto Y, Torii M, Takeshige F, Ebisu S. Polymerization contraction stress of resin composite restorations in a model class I cavity configuration using photoelastic analysis. J Esthet Dent. 2000;12(6):309-19.
PPD showed a slight potential for minimizing polymerization shrinkage stress immediately after photoactivation.

\section{Acknowledgments}

This report is based on a thesis submitted to the Piracicaba Dental School, State University of Campinas, in partial fulfillment of the requirements for the Master's degree. This investigation was supported by CAPES (Coordenação de Aperfeiçoamento de Pessoal de Nível Superior) at Piracicaba Dental School, UNICAMP.

\section{References}

1. Davidson CL, Feilzer AJ. Polymerization shrinkage and polymerization shrinkage stress in polymer-based restoratives. J Dent. 1997 Nov;25(6):435-40

2. Davidson CL. Handling the polymerization stresses - Restorative Dentistry in resin-based restorative materials. Dental News. 2000;VII(IV):9-13.

3. Pearson J, Bouschlicher MR. Polymerization contraction force of packable composites. Gen Dent. 2001 Nov-Dec;49(6):643-7.

4. Ernst CP, Meyer GR, Klocker K, Willershausen B. Determination of polymerization shrinkage stress by means of a photoelastic investigation. Dent Mater. 2004 May;20(4):313-21.

5. Atai M, Watts DC, Atai Z. Shrinkage strain-rates of dental resin monomer and composite systems. Biomaterials. 2005 Aug;26(24):5015-20.

6. Weinmann W, Thalacker C, Guggenberger R. Siloranes in dental composites. Dent Mater. 2005 Jan;21(1):68-74.

7. Ilie N, Jelen E, Clementino-Luedemann T, Hickel R. Lowshrinkage composite for dental application. Dent Mater J. 2007 Mar;26(2):149-55.

8. Stansbury JW. Curing dental resins and composites by photopolymerization. J Esthet Dent. 2000;12(6):300-8

9. Park Y-J, Chae K-H, Rawls HR. Development of a new photoinitiation system for dental light-cure composite resins. Dent Mater. 1999 Mar;15(2):120-7.

10. Schneider LFJ, Pfeifer CSC, Consani S, Prahl AS, Ferracane JL. Influence of photoinitiator type on rate of polymerization, degree

12. Ainola L, Aben H. Principal formulas of integrated photoelasticcity in terms of characteristic parameters. J Opt Soc Am A Opt Image Sci Vis. 2005 Jun;22(6):1181-6.

13. Pereira MGP, Smith Neto T, Almeida ID. Avaliação de franjas fotoelásticas simuladas no matlab e software de elementos finitos. $8^{\circ}$ Congresso Iberoamericano de Engenharia Mecanica; 2007 Oc- 
tober, 23; Cusco, Peru. Cusco: Editora PUCP; 2007. 1-8. Disponível em http://www.congreso.pucp.edu.pe/cibim8/pdf/27/27-05.pdf.

14. Vásquez-Rodríguez JM, Herrera-Franco PJ, Gonzalez-Chi PI. Micromechanical analysis of thermoplastic - thermoset interphase. Macromol Symp. 2004 Sep;216(1):117-29.

15. Souza FL, Cleudmar AA. Fotoelasticidade Automatizada Utilizando Luz Polarizada Elíptica. Horizonte Científico. 2007;1(1):113.

16. Braga RR, Ballester RY, Ferracane JL. Factors involved in the development of polymerization shrinkage stress in resin-composites: a systematic review. Dent Mater. 2005 Oct;21(10):962-70.

17. Ogunyinka A, Palin WM, Shortall AC, Marquis PM. Photoinitiation chemistry affects light transmission and degree of conversion of curing experimental dental resin composites. Dent Mater. 2007 Jul;23(7):807-13.

18. Musanje L, Ferracane JL. Effects of resin formulation and nanofiller surface treatment on the properties of experimental hybrid resin composite. Biomaterials. 2004 Aug;25(18):4065-71.

19. Eick JD, Kotha SP, Chappelow CC, Kilway KV, Geise GJ, Glaros $\mathrm{AG}$, et al. Properties of silorane-based dental resins and composites containing a stress-reducing monomer. Dent Mater. 2007 Aug;23(8):1011-7.

20. Loguercio AD, Reis A, Schroeder M, Balducci I, Versluis A, Ballester RY. Polymerization shrinkage: effects of boundary conditions and filling technique of resin composite restorations. J Dent. 2004 Aug;32(6):459-70. 